\title{
Development of 3D Printing Technology for Geopolymers
}

\author{
Kinga Korniejenko, Michał Lach, Janusz Mikuła, Maria Hebdowska-Krupa, Dariusz \\ Mierzwiński, Szymon Gądek and Marek Hebda
}

Institute of Materials Engineering, Faculty of Materials Engineering and Physics, Cracow University of Technology, Jana Pawła II 37, 31-864 Cracow, Poland, michal.lach@pk.edu.pl

\begin{abstract}
The article presents the first results of the project under the title: 'Development of $3 D$ printing technology for construction and facade prefabricated elements made of concrete composites and geopolymers', grant no. POIR.04.01.04-00-0096/18, funded by the National Centre for Research and Development in Poland, within the framework of programme: 'Smart Growth Operational Programme 2014-2020, IV Increasing the research potential, 4.1.4: 'Application projects'. The main aim of the project is design and development of the innovative large-format printer using geopolymers for $3 D$ printing for residential houses. It allows the development of a technology for the production of a universal residential building, with a construction that is easy to transport and fast to assemble, as well as with the possibility of simple and quick expansion depending on the needs of users. The article shows the main idea of the advanced large format $3 D$ printing for geopolymers with using an ergonomic printing method as well as materials research in modern filaments in the form of geopolymers.
\end{abstract}

Keywords: Geopolymer, 3D Printing, Additive Manufacturing, Large-Format 3D Printer, $3 D$ Printing in Civil Engineering.

\section{Introduction}

Additive Manufacturing is a rapidly developing industrial sector and potentially a disruptive technology. It can provide new horizons in the construction sector, especially in terms of geometrical flexibility, reduction of labour costs, improvement of efficiency and safety, construction in harsh environments, and sustainability (Nematollahi et al., 2019; Labonnote et al., 2016; Panda and Tan, 2019; Soltan and Li, 2018). Unfortunately, the full exploitation of 3D printing processes is currently limited due to the in-process and in-service performance of the available materials' sets, especially in application in construction industry.

Nowadays, the using geopolymers for 3D printing in the large-format printer is a great challenge. It offers a new perspectives for the construction industry, but the development of this technology is slowed down by a lot of barriers. The article shows the possibility of development the $3 \mathrm{D}$ printing. The main idea of development the advanced large format $3 \mathrm{D}$ printing for geopolymers is using an ergonomic printing method as well as materials research in modern filaments in the form of geopolymers. The article is focused on problems that appear during the first trials of development 3D printing technology.

The first research were connected with basic properties of the materials - key factors of effectiveness 3D printing process, such as: viscosity and time of bonding (Labonnote et al., 2016; Rahul et al., 2019). This basic properties are related with the thixotropic, and allow to understood as high yield strength and low viscosity behavior of the materials, including (Labonnote et al., 2016; Panda and Tan, 2019):

- pumpability - reliability with which material is moved through the delivery system,

- extrudability - depositing material through a deposition device, 
- buildability - resistance of wet material to deformation under loads,

- $\quad$ and open time - period during which the aforementioned properties remain consistently within acceptable tolerance.

The basic challenge in $3 \mathrm{D}$ printing is received the material that is sufficiently fluid and at the same time has sufficient viscosity to retain its shape after the printing process (Panda and Tan, 2019; Panda et al., 2018). Moreover, not only the material properties decided about the possibilities of effective process. The other elements associated with technology are also important. All of this factors happen that there is only a limited understanding of the material requirements for 3D printing technology (Labonnote et al., 2016; Rahul et al., 2019).

\section{Materials}

The samples for small scale prototyping were prepared with metakaolin with pigment addition.

The samples for large scale were prepared as geopolymer concrete, based on:

metakaolin and sand (ratio: 1:1),

fly ash and sand (ratio: $1: 1$ ).

Both raw material, fly ash as well as metakaolin, were thoroughly investigated as a possible raw material for the production of the geopolymers. The chemical composition was determined by X-ray fluorescence (WD-XRF). They oxide composition is shown in Table 1.

Table 1. Oxide composition of fly ash and metakaolin.
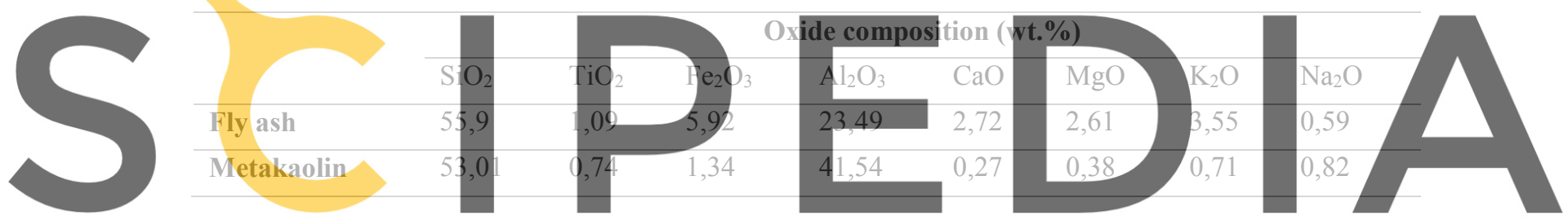

Geopolymers were made from fly ash from the metakaolin or fly ash and sand in ratio 1:1.

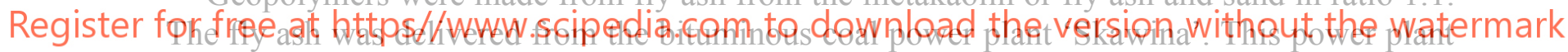

is located in Skawina in Lesser Poland region on the south of Poland. The fly ash is obtained

as combustion by-product through the electrostatic precipitation of fine particles from the exhaust gases from coal-fired furnaces. The chemical composition of this fly ash is relevant for the geopolymerization process - it is typical for class F (Lach et al., 2016). The detailed oxide composition is presented in Table1. This raw material contains less than 5\% of unburned material and less than $10 \%$ of iron compounds. Additionally it has low amount calcium compounds. The amount of the reactive silica in the material is ca. $36 \%$. Moreover, it has physical parameters relevant to geopolymers manufacturing, especially it contains a lot of spherical particles and has good workability ( Łach et al., 2018) as well as large amount of amorphous phase ( Lach et al., 2016). The process of activation has been made by $10 \mathrm{M}$ sodium hydroxide solution combined with the sodium silicate solution (the ratio of liquid glass $-1: 2.5$ ).

\section{3D Printing of Small Scale Elements}

Samples were prepared using sodium promoter for activation the metakaolin with some pigment addition. The trials has been made on the laboratory $3 \mathrm{D}$ printer for concrete - WASP 2040 with pneumatic feeder. 
The samples some multilayers plate have been prepared using 3D printing method - Figure 1. The printed samples were characterized by different quality.

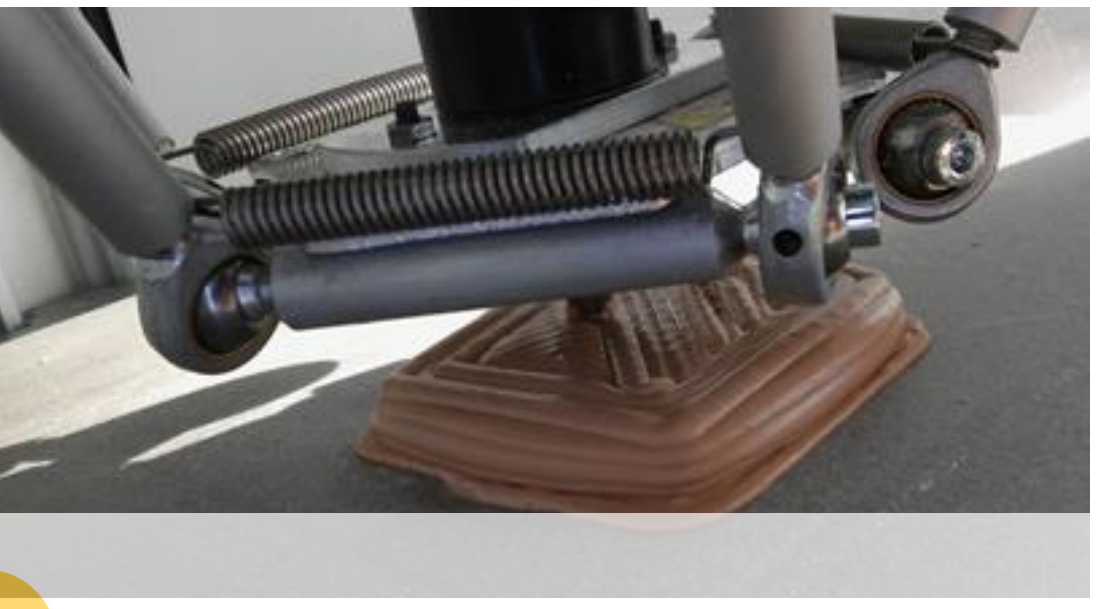

Figure 1. Page layout.

The most important problem was viscosity of the material. In the first trials the material was too solid and the process was impossible to print effectively (Figure 2b), but the layers in this case were created effectively. The samples had ratio between liquid and solid parts: $\mathrm{c} / \mathrm{s}=0.25$ Because of the lack of possibility of printing the viscosity was regulated by ethanol addition. After receiving the requilred viscosity the main ratio between liquid and solid parts: $\mathrm{c} / \mathrm{s}=0.3$. the main problems was connected with lack of of that the product loss they shape.
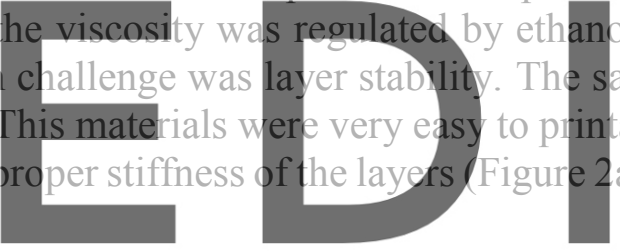

Register for free at https//www.scipedia.com to download the version without the watermark

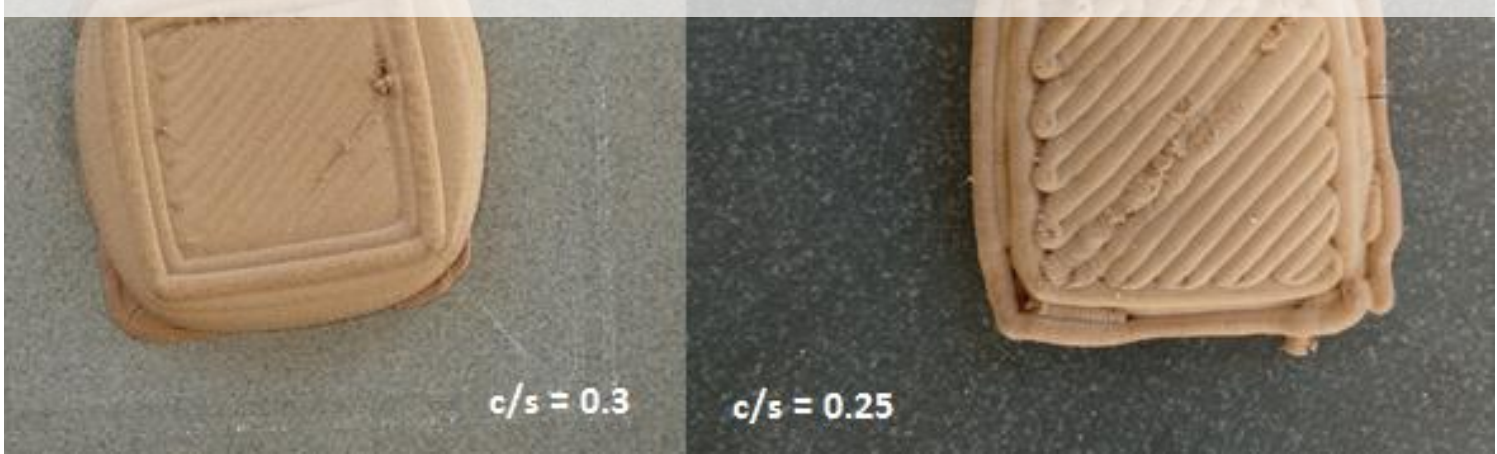

Figure 2. Samples after 3D printing with different liquid/solid ratio a) 0.3, b) 0.25 .

The ratio between $\mathrm{c} / \mathrm{s}$ required modification, but main problem is too long period for receiving the proper stiffness it must be analyzing once again and modify by proper addition on introducing some factors that accelerate the bonding such as additional sources of 
temperature (Bong et al., 2019; Nematollahi et al., 2019).

The other challenge was brittle material behavior after the curing time and cracking during the drying process (Figure 3 ).

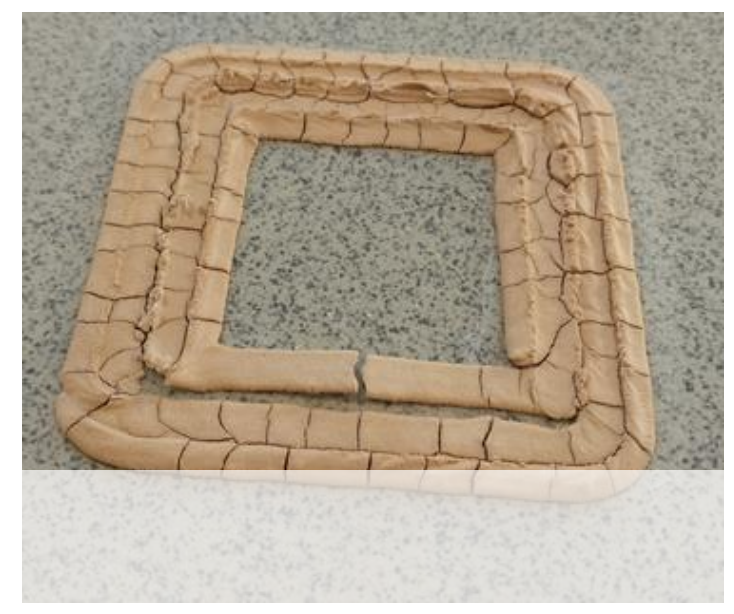

Figure 3. Samples after drying with visible cracks.

The problem of the cracks required introducing the additives to the geopolymer. It could be for example fibers addition that reduced the brittle material behavior (Korniejenko et al., 2018; Nematollahi et al., 2018; Silva etal, 2020). 4 3D Printing for Large-Scale Elements - Manual Pr. Printing Process

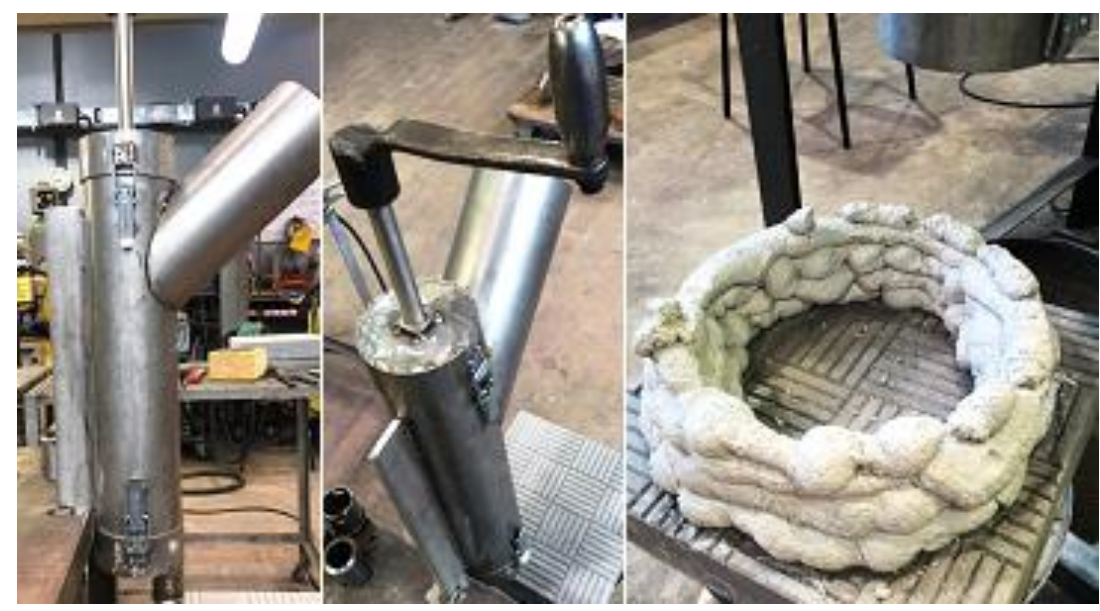

Figure 4. Self- produced manual 3D printing machine. 
The trials were conducted on the large form with using different ratio liquid and solid parts - Figure 5.

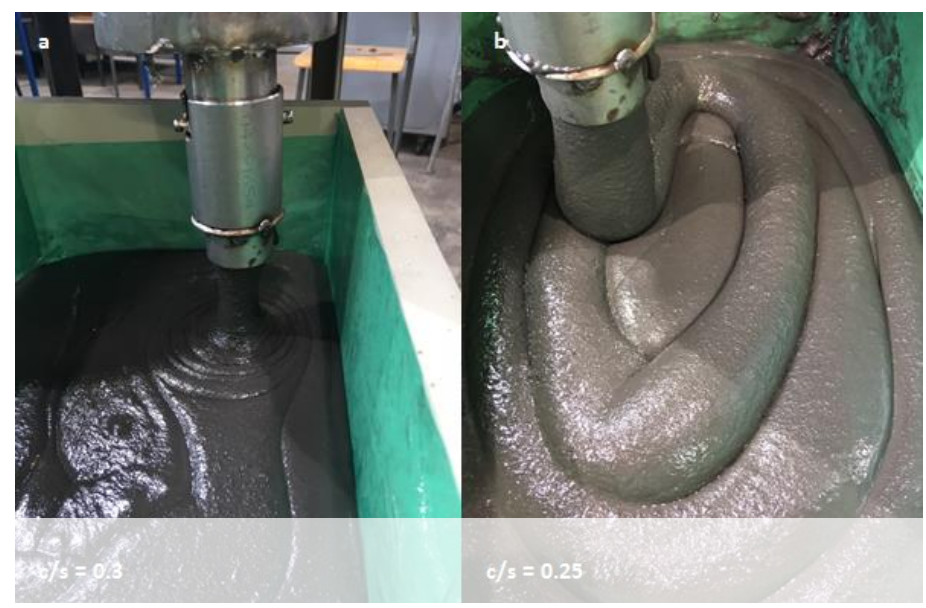

Figure 5. Samples after 3D printing with different liquid/solid ratio a) 0.3 , b) 0.25

The achieved results did not fulfil the requirements. The samples produced with different kind of ratio were too liquid to application for building elements. The material need further modification.

\section{Conclusions}

The article is focused on technology, especially large scale elements
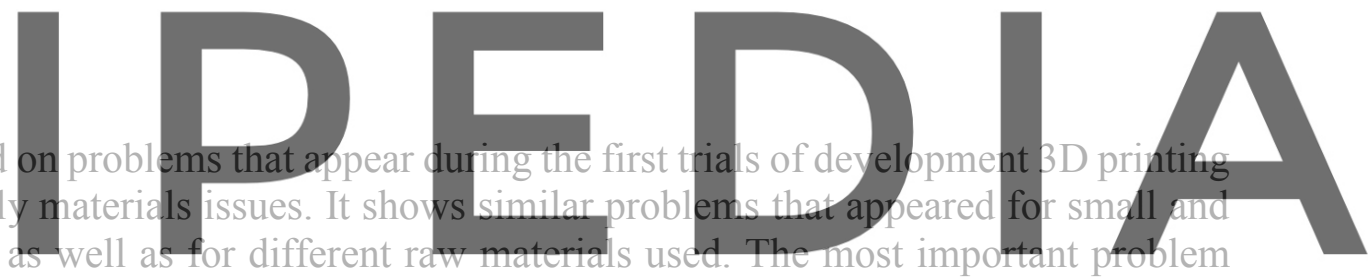
was viscosity the material. It was regulated by ratio between liquid and solid parts and additives

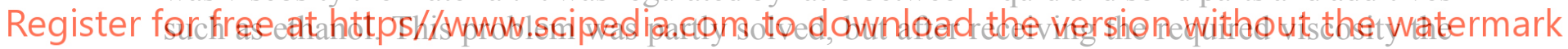
main challenge was layer stability. There are planned further work on material stabilization.

The other challenge was brittle material behavior after the curing time and cracking during the drying process. The solving of this challenge required further works, especially connecting with design of proper curing process.

\section{Acknowledgements}

This work has been supported by Smart Growth Operational Programme 2014-2020, IV Increasing the research potential, 4.1.4: Application projects, funded by the National Centre for Research and Development in Poland, within the framework of the grant: Development of 3D printing technology for construction and facade prefabricated elements made of concrete composites and geopolymers, grant no. POIR.04.01.04-00-0096/18.

\section{ORCID}

Kinga Korniejenko: https://orcid.org/0000-0002-8265-3982

Michał Łach: https://orcid.org/0000-0001-5713-9415

Janusz Mikuła: https://orcid.org/0000-0001-9514-7870

Maria Hebdowska-Krupa: N/A

Dariusz Mierzwiński: https://orcid.org/0000-0003-2292-3546

Szymon Gądek: N/A 
Kinga Korniejenko, Michał Łach, Janusz Mikuła, Maria Hebdowska-Krupa, Dariusz Mierzwiński, Szymon

Gadek and Marek Hebda

Marek Hebda: https://orcid.org/0000-0002-8583-9459

\section{References}

Bong, S.H., Nematollahi, B., Nazari, A., Xia, M. and Sanjayan, J. (2019) Method of Optimisation for Ambient Temperature Cured Sustainable Geopolymers for 3D Printing Construction Applications Materials, $12,902$. doi: $10.3390 / \mathrm{ma} 12060902$

Korniejenko, K., Łach, M., Hebdowska-Krupa, M. and Mikuła J. (2018). The mechanical properties of flax and hemp fibres reinforced geopolymer composites IOP Conference Series: Materials Science and Engineering, 379, 012023. doi: 10.1088/1757-899X/379/1/012023

Labonnote, N., Rønnquist, A., Manum, B. and Rüther, P. (2016). Additive construction: State-of-the-art, challenges and opportunities Automation in Construction, 72(3) 347-366. doi: 10.1016/j.autcon.2016.08.026

Łach, M., Korniejenko, K. and Mikuła J. (2016). Thermal insulation and thermally resistant materials made of geopolymer foams Procedia Engineering, 151, 410-416. doi: 10.1016/j.proeng.2016.07.350

Łach, M., Mierzwiński, D., Korniejenko, K. and Mikuła, J. (2018). Geopolymer foam as a passive fire protection MATEC Web of Conferences, 247, 00031. doi: 10.1051/matecconf/201824700031

Nematollahi, B., Vijay, P., Sanjayan, J., Nazari, A., Xia, M., Nerella, V.N. and Mechtcherine, V. (2019). Effect of Polypropylene Fibre Addition on Properties of Geopolymers Made by 3D Printing for Digital Construction Materials, 11(12), 2352. doi: 10.3390/ma11122352

Nematollahi, B., Xia, M. and Sanjayan J. (2019). Post-processing Methods to Improve Strength of Particle-Bed 3D Printed Geopolymer for Digital Construction Applications Frontiers in Materials, 6, 160. doi: 10.3389/fmats.2019.00160

Panda, B. and Tan, M.J. (2019). Rheological behavior of high volume fly ash mixtures containing micro silica for digital construction application Materials Letters, 237, 348-351. doi: 10.1016/j.matlet.2018.11.131

Panda, B. Unluer, C. and Tan, M.J. (2018). Investigation of the rheology and strength of geopolymer mixtures for

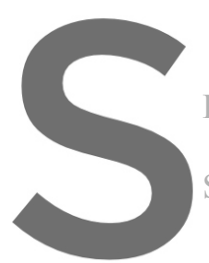
extrusion-based 3D 10.1016/j.cemconcomp. 2 .

Rahul, A.V., Santhanam, methods, Cement and

Silva, G., Kim, S., Aguilar, - A review of potential Technologies, 23, e00132.
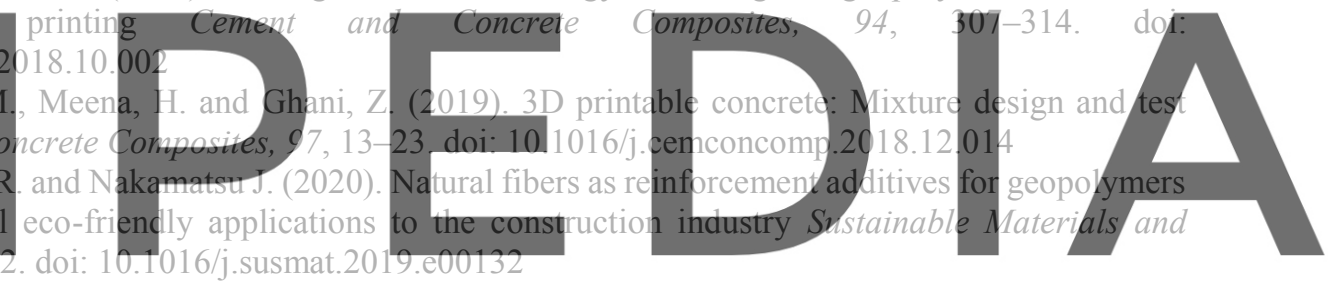

Soltan, D.G. and Li, V.C. (2018). A self-reinforced cementitious composite for building-scale 3D printing Cement

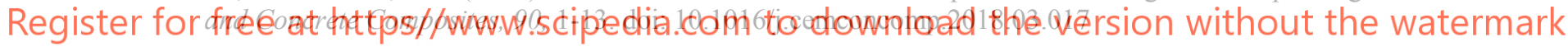

